\title{
Latitudinal variation of Adh gene frequencies in Drosophila melanogaster: a Mediterranean instability
}

\author{
J. R. David, ${ }^{*}$ \\ Angeles Alonso-Moraga, $\dagger$ \\ F. Borai, $\$$ \\ P. Capy, \\ H. Merçot, $\S$ \\ S. F. McEvey, \\ A. Munoz-Serrano $†$ and \\ S. Tsakas"
}

\author{
* Laboratoire de Biologie et Génétique évolutives, \\ CNRS, 91198 Gif sur Yvette, France. \\ $\dagger$ Departmento de Genetica, Universidad de Cordoba, \\ 14005 Cordoba, Spain. \\ $\ddagger$ Department of Genetics, Faculty of Agriculture, \\ University of Alexandria, Alexandria, Egypt. \\ \$ Laboratoire de Génétique des populations, associé \\ au CNRS, Université Paris VII, 75251 Paris Cedex 05, \\ France. \\ "Department of Genetics, Agricultural College, \\ Athens, Greece.
}

The relationship between allelic frequencies at the $A d h$ locus and latitude of origin was studied using selected published data from various parts of the world and original observations. An overall increase of $A d h-F$ with increasing latitude was observed but the relationship is not linear. Tropical populations are generally similar, having a low frequency of the $F$ allele (average 15 per cent) and a smooth increase with latitude (one per cent for one degree). Between 30 and $42^{\circ}$ latitude, populations living in a Mediterranean climate in various parts of the world (Mediterranean countries, Australia's east coast and North America's west coast) are also similar, with a much higher average frequency of $F$ (70 per cent), a steeper slope (two per cent) and a broader range of variability for a given latitude. In a restricted area (near Cordoba in southern Spain) numerous wild collected samples also showed a large variability, sometimes over a very short distance. Allelic frequencies in Mediterranean countries are thus quite unstable and it is proposed that this phenomenon be called a "Mediterranean instability". Further north, numerous samples from France were characterized by an even higher frequency of $F$ ( 95 per cent) and a greater homogeneity over a broad geographic area. These observations are discussed and the need for more field studies is emphasized.

\section{INTRODUCTION}

The observation of similar or parallel clines on different continents strongly suggests that they have adaptive significance (Oakeshott et al., 1982; Anderson and Oakeshott, 1984; Endler, 1986) and are not the product of random colonization events. For the $A d h$ (alcohol dehydrogenase) locus in Drosophila melanogaster, the frequency of the $F$ allele is known to increase with latitude in different parts of the world, such as North America (Johnson and Schaffer, 1973; Smith et al., 1984) and Australia and Asia (Oakeshott et al., 1982). More recently, a similar tendency (David et al, 1986) was observed between tropical Africa, which harbours the ancestral populations of the species (Lachaise et al., 1988), and Europe, and also in the southern hemisphere between the Equator and southern Africa. In most previous studies, the relationship between latitude and gene frequency was determined by calculating the coefficient of linear correlation, $r$, thus making implicit the assumption that the cline was linear. However, data from European and African populations (David et al., 1986) suggests that the cline is not linear. Tropical and subtropical populations have a very low frequency of the $F$ allele, French populations a very high frequency, while intermediate populations in countries with a Mediterranean climate, in southern Europe and north Africa, are steeply graded between these two levels.

We have extended this analysis by considering many more populations from places with a Mediterranean climate i.e., a humid, mild and rainy winter and a dry, hot summer. We show that "Mediterranean" populations in various parts of the world are similar i.e., they have an apparently steep cline with latitude. However, a steep cline means that, for a given latitude, a large range of allelic frequencies may be observed, suggesting a loose relationship between the two variables. Indeed, by considering numerous samples collec- 
ted in southern Spain (Cordoba vicinity) in different habitats, seasons and years, we found that $A d h$ gene frequencies are extremely variable in the same geographic area. We propose to call this phenomena a "Mediterranean instability" and its significance for ecological genetics is discussed.

\section{MATERIAL AND METHODS}

This study focused on populations living around the Mediterranean sea: we included data from Grossman (1973), Aguade and Serra (1980), Alonso-Moraga et al. (1985), David et al. (1986) and unpublished observations. For a latitudinal transect, we sampled in the same range of longitudes, since longitudinal variations are known to occur between continents (Oakeshott ef al., 1982). We consider French populations, of which we have many samples (Girard and Palabost, 1976; Charles-Palabost et al., 1985; David et al., 1986; and unpublished data) to be representative of those living at high latitude and under a cool temperature climate. Tropical and equatorial populations were taken from the African mainland south of the Sahara (David et al., 1986).
We investigated other populations, from various parts of the world with a Mediterranean climate. These were from southern Africa (David et al., 1986), Australia (Oakeshott et al., 1982) and the west coast of America (Smith et al., 1984). On a latitudinal plot, all populations could fall within the range of variation found around the Mediterranean Sea: they were thus included in the present analysis. The Australian samples were especially interesting because they lived in geographic continuity with tropical populations from lower latitudes. The Australian tropical populations were found to be similar to those in tropical Africa and are also included in the present study.

Three latitudinal groups of populations will be considered here: (1) tropical populations living between the Equator and $30^{\circ}$ of latitude and taken from Africa and Australia; (2) "Mediterranean" populations living between 30 and $42^{\circ}$ of latitude and including all the presently available data in the various parts of the world where a Mediterranean climate exists; (3) cool temperature populations, above $42^{\circ}$ of latitude and taken only from France.

For tropical and cool temperate populations, variations occurring with longitude and especially

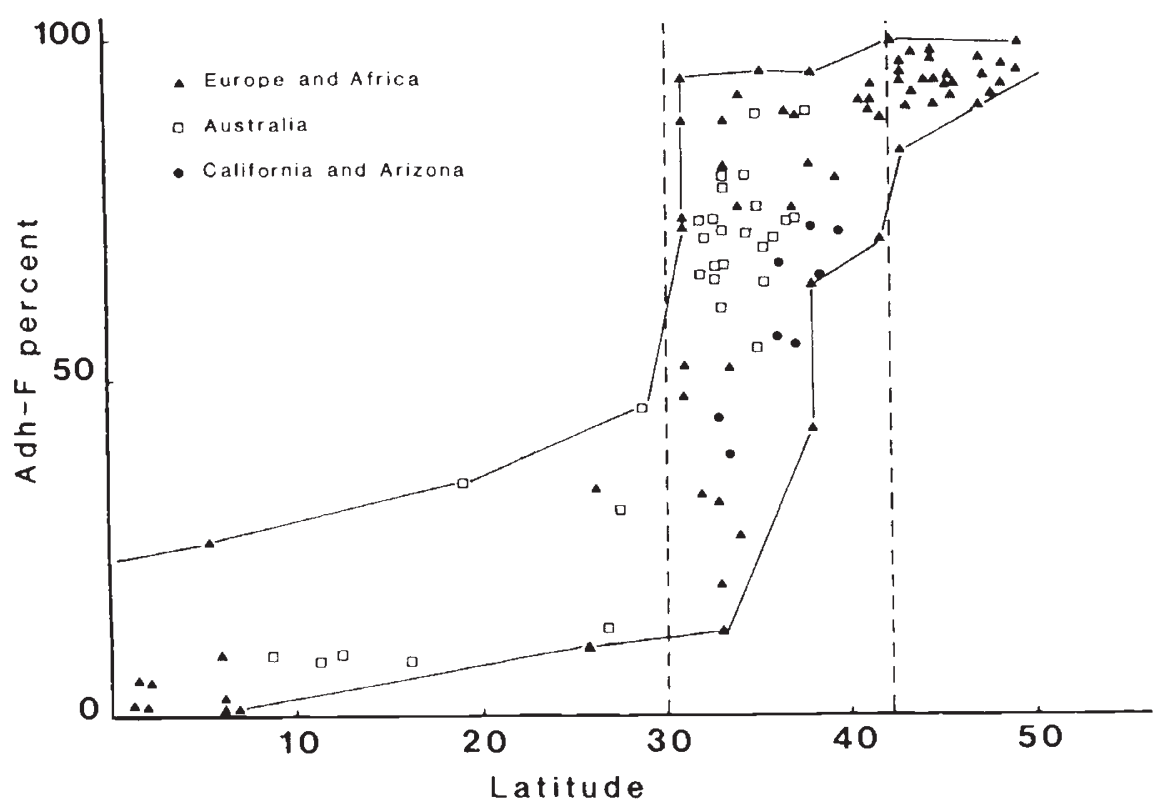

Figure 1 Relationship between Adh-F frequency and latitude in natural populations of Drosophila melanogaster. Below $30^{\circ}$ of latitude, results are taken from Africa (David et al., 1986) and from Australia (Oakeshott et al., 1982). Between 30 and $42^{\circ}$ of latitude, only populations living under a Mediterranean climate are considered: data from Oakeshott et al. (1982) (Australia), Smith et al. (1984) (California), Grossman (1973), Aguade and Serra (1980) and David et al. (1986) (countries around the Mediterranean Sea) and unpublished data. Above $42^{\circ}$ of latitude only French populations are considered; data from Girard and Palabost (1976), Charles-Palabost et al. (1985), David et al. (1986) and unpublished observations; only 25 random points are shown on the graph for clarity. Published values based on less than 40 genes were not considered. 
between continents, will be considered in the discussion. Among the Mediterranean populations, numerous samples were collected around Cordoba (southern Spain) over a limited geographic area (Alonso-Moraga et al., 1985; Munoz-Serrano et al., 1985; Alonso-Moraga and Munoz-Serrano, 1986, and unpublished data), confirm the other observations.

$A d h$ gene frequencies were calculated after gel electrophoresis and staining for enzyme activity. In most cases, more than 100 alleles were studied in each sample, but the variations in the sample sizes are not taken into account in this study. However, samples of less than 15 individuals were discarded.

\section{RESULTS}

The variation $A d h-F$ frequencies with latitude are shown in fig. 1 and some statistical analyses are given in table 1. Although the overall linear correlation is very high $(r=0.89)$, the regression of the $F$ frequency with latitude is not linear. Inspection of the figure suggests that the empirical data may be split into three different groups which broadly correspond to different climates.

Between the Equator and about $30^{\circ}$ North or South, populations live under tropical conditions which are characterized by an average temperature above $20^{\circ} \mathrm{C}$ and low seasonal variation. In all populations from the African mainland and Australia the $A d h-F$ frequency is low, with an average value of 13.5 per cent. Also, a slight but significant increase of the $F$ frequency occurs with latitude, about one per cent for one degree of latitude. The overall variability between these populations may be appreciated by considering the fixation index, $F_{\text {ST }}$ (Wright, 1951) which is 0.15 (table 1).

Between 30 and $42^{\circ}$ latitude, the populations were living under a Mediterranean climate, characterized by a low average temperature and marked seasonal variation: dry hot summers and mild, rainy winters. Interestingly, populations collected around the Mediterranean Sea, on the east coast of Australia and on the west coast of America have similar properties, these data are pooled. These "Mediterranean" populations are characterized by a high average frequency of the $F$ allele (70 per cent ) a low correlation with latitude $(r=0 \cdot 33)$ but a steeper slope. The genetic variability between these 58 samples is high, as indicated by the fixation index of $0 \cdot 16$.

Above $42^{\circ}$ of latitude, only French populations are considered, for which numerous data are available. Some of these populations were also living under Mediterranean conditions, for example the sample from Perpignan (southern France) and another from Corsica, with $A d h-F$ frequencies of 83 and 99 per cent respectively. However, on average, French populations live under a much cooler climate (the annual average temperature in Paris is $13^{\circ} \mathrm{C}$ ) with a cold winter. Also, rain is distributed more evenly between seasons. Between 42 and $49^{\circ}$, there is no significant increase of the $F$ frequency. Moreover, the overall frequency is very high ( 94.9 per cent) while the between sample variability is much reduced (fixation index of $0 \cdot 02$ ).

Examination of fig. 1 suggests that there is a very steep cline of $A d h-F$ frequency in Mediterranean countries. On the other hand, the results may be interpreted as a loose relationship with latitude. For example, at a latitude close to $33^{\circ}$, we find extreme values of $12 \cdot 3$ per cent in Israel

Table 1 Adh-F frequency and latitudinal relationships in populations from various geographic origins living under different climates. $N$ : Number of populations; $r$ : coefficient of correlation $\left({ }^{*} P<0.05 ; * * P<0 \cdot 01\right)$; $b$ : coefficient of regression; $F_{\mathrm{ST}}$ : fixation index between populations

\begin{tabular}{|c|c|c|c|c|c|c|c|}
\hline \multirow[b]{2}{*}{ Climatic conditions } & \multirow[b]{2}{*}{ Geographic origin } & \multirow[b]{2}{*}{$N$} & \multicolumn{3}{|c|}{ Latitudinal relationship } & \multicolumn{2}{|c|}{ Adh-F frequency } \\
\hline & & & Range & $r$ & $b$ & Mean $(\%)$ & $\mathrm{F}_{\mathrm{ST}}$ \\
\hline \multirow[t]{3}{*}{ Tropical } & Africa & 11 & $2 \cdot 5-26 \cdot 2$ & $0.57^{*}$ & 0.74 & $9 \cdot 05 \pm 3 \cdot 17$ & $0 \cdot 134$ \\
\hline & Australia & 8 & $8 \cdot 8-28 \cdot 7$ & $0 \cdot 72^{*}$ & $1 \cdot 36$ & $19 \cdot 62 \pm 5 \cdot 26$ & $0 \cdot 123$ \\
\hline & Total & 19 & & $0 \cdot 70^{* *}$ & 0.99 & $13 \cdot 50 \pm 3 \cdot 10$ & $0 \cdot 148$ \\
\hline \multirow[t]{4}{*}{ Mediterranean } & Mediterranean Sea & 28 & $31-41 \cdot 8$ & $0 \cdot 38^{*}$ & $2 \cdot 49$ & $71 \cdot 36 \pm 4 \cdot 66$ & $0 \cdot 287$ \\
\hline & Australia & 22 & $31 \cdot 9-37 \cdot 7$ & $0 \cdot 19$ & 0.80 & $71 \cdot 32 \pm 1 \cdot 60$ & 0.026 \\
\hline & N. America & 8 & $32 \cdot 9-39 \cdot 7$ & $0.91^{* *}$ & $4 \cdot 82$ & $59 \cdot 04 \pm 4 \cdot 54$ & $0 \cdot 060$ \\
\hline & Total & 58 & & $0 \cdot 33^{* *}$ & 1.98 & $69 \cdot 64 \pm 2 \cdot 45$ & $0 \cdot 161$ \\
\hline Cool temperate & France & 51 & $42-49$ & $0 \cdot 21$ & $0 \cdot 34$ & $94 \cdot 90 \pm 0 \cdot 45$ & $0 \cdot 020$ \\
\hline Grand total & & 131 & $2 \cdot 5-49$ & $0.89^{* *}$ & $2 \cdot 32$ & $71 \cdot 20 \pm 2 \cdot 66$ & 0.445 \\
\hline
\end{tabular}


(Grossman, 1973) and of 88 per cent in Iraq (David et al., 1986). Of course, the samples considered in fig. 1 were taken in different, often very distant countries so that much of the variability could be attributed to area effects and isolation by distance. So, we may ask: What is the amount of genetic variability in a limited geographic area? To answer this question, we considered the results from the vicinity of Cordoba in southern Spain, and published in several papers (Alonso-Moraga et al., 1985, Munoz-Serrano et al., 1985, Alonso-Moraga and Munoz-Serrano, 1986). The maximum distance between these samples is less than $200 \mathrm{~km}$,

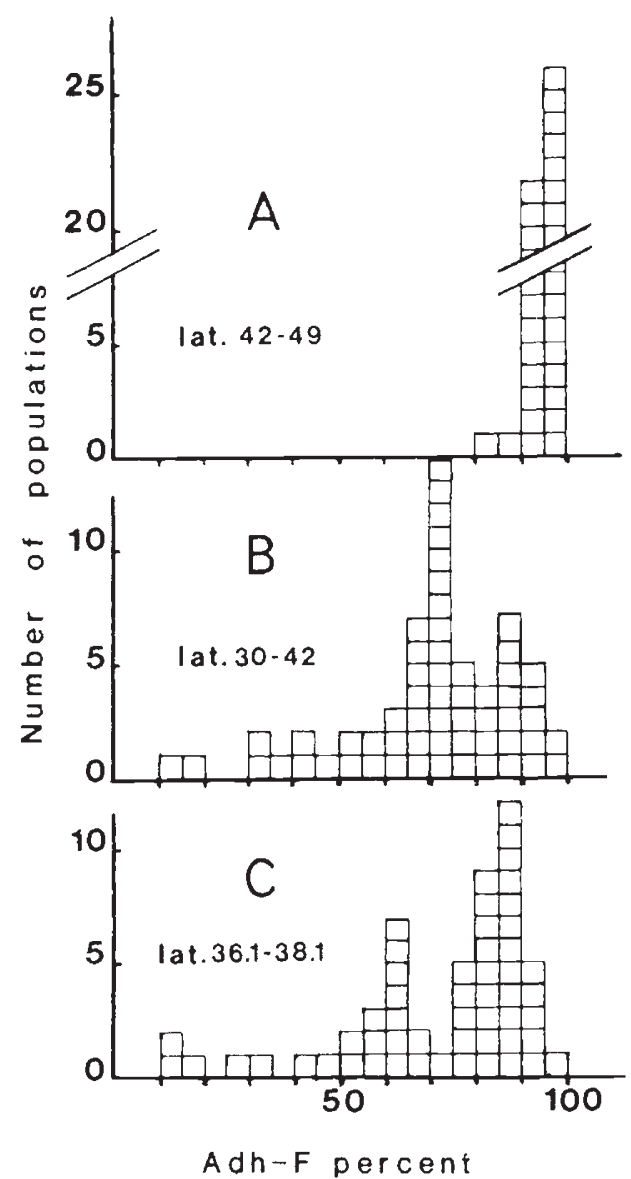

Figure 2 Frequency distribution of the percentage of $A d h-F$ allele in natural populations for various latitudes and geographic areas. (a) Distribution of 51 samples from France. (b) Distribution of 58 samples collected in various parts of the world, in countries with a Mediterranean climate. (c) Distribution of 54 samples collected in southern Spain around Cordoba; data from Alonso-Moraga et al. (1985), Munoz-Serrano et al. (1985), Alonso-Moraga and MunozSerrano (1986) and unpublished; values in graph $\mathrm{c}$ are not included in graph $b$. most were collected over successive years within a radius of $30 \mathrm{~km}$ around Cordoba. The distribution of 54 samples is given in fig. 2(c) and compared (fig. 2(b)) to that of the 58 worldwide samples shown in fig. 1. The two distributions are remarkably similar, the Cordoba samples have an average Adh-F frequencies of $70.5 \pm 2.9$ per cent and a fixation index of $0 \cdot 21$. This is in marked contrast with the stability of the French populations (fig. $2(\mathrm{a}))$ collected over a much broader area. In other Mediterranean countries, D. melanogaster populations also appeared quite variable over a short geographic distance. In Athens (Greece, latitude $38^{\circ}$ ), samples collected exactly at the same place but in different years and seasons, ranged between 42 and 81 per cent of $A d h-F$. In Alexandria (Egypt, latitudes $31^{\circ}$ and $31.1^{\circ}$ ) and its immediate vicinity the extreme frequencies were 47 and 88 per cent for this allele. Therefore, at least in countries around the Mediterranean Sea, local populations of $D$. melanogaster are quite unstable with respect to their $A d h$ allelic frequencies.

\section{DISCUSSION AND CONCLUSION}

The data presented here represent only a subset of what is published on the $A d h$ locus in natural populations of $D$. melanogaster. In all countries which have been surveyed to date, an increase of the frequency of the $F$ allele with latitude has been found and, as repeatedly stated, this is strong evidence that the cline has adaptive significance. However, less attention has been paid to the shape of the cline, to the mean values observed at similar latitudes on different continents and to the variability of local populations. It is hoped that the present paper will stimulate further comparative studies of this type.

The low frequency of the $F$ allele in tropical populations seems also to be a general phenomenon on the American continent. For example, in the French West Indies, frequencies of $F$ in the range 0 and 1.9 per cent have been described (Capy et al., 1986). In tropical Asia, the situation is far less obvious. Oakeshott et al. (1982), on the basis of a small subset of Asiatic populations, suggested a significant increase of $A d h-F$ with latitude. On the other hand, a tropical population from Vietnam (Ho-Chi-Minh-ville, latitude $11^{\circ}$ ) was found to be homozygous for the $F$ allele (Singh et al., 1982): more extensive investigations of Far-Eastern populations are obviously needed.

European populations, at latitudes between 42 and $50^{\circ}$, are poorly known. On the basis of a few 
observations from northern Italy, Germany and the Soviet Union (Grossman et al., 1970; David, 1982; David et al., 1986 and unpublished results), it seems that the proportion of $A d h-F$ stays above 90 per cent, suggesting that such a high frequency in this latitudinal range is a European phenomenon. By contrast, populations living at similar latitudes and under similar climatic conditions on the East coast of North America differ greatly, the average $F$ frequency is around 50 per cent (Johnson and Schaffer, 1973). On the East coast there is a geographic continuity between subtropical and cold temperate conditions with a progressive increase of the average annual temperature but without the special features of a Mediterranean climate. Interestingly, in that part of the world, the genetic cline seems linear (Johnson and Schaffer, 1973). Such intercontinental variations may reflect local adaptations but also historical events related to the colonization of new places by D. melanogaster (David and Capy, 1988).

The similar results found in three distart geographic regions, which are all characterized by a Mediterranean climate, are interesting since they have very different histories (David and Capy, 1988). Of course, this convergence will need further investigation and it seems premature to look for definitive interpretations although some suggestions can be made.

The polymorphism at the $A d h$ locus has been the subject of intensive investigations and it is generally assumed that it is maintained by natural selection (see Van Delden, 1982). Among the selective factors which are generally invoked, the amount of alcohol in larval resources is most often considered: the proliferation of $D$. melanogaster in wine cellars is accompanied by a high ethanol tolerance and a high frequency of the more active $F$ allele (David et al, 1986). Temperature is also often considered as a potential selective factor and the prevalence of the $S$ allele in tropical places could be attributed to a better heat tolerance of this protein (Van Delden, 1982). Other environmental factors may also be significant; for example, Oakeshott et al. (1982) found a clear relationship between rainfall and the frequency of the $F$ allele, but this relationship was not confirmed in a more recent study (Anderson et al., 1987).

Whatever the selective pressure, the genetic stability of a polymorphism, as it is observed either in the tropics or in a temperate country like France, seems to be due to some kind of balancing selection. The argument is still stronger if we consider that attempts to modify the genetic structure of such populations by releasing flies genetically marked with the rarer allele, have failed (David, 1983; Capy et al., 1988).

In Mediterranean countries, the genetic instability of natural populations could be explained by a lack of selection, so that the observed variations would mainly reflect stochastic events, i.e., the occurrence of small, subdivided populations in a patchy environment, with high rates of extinction and of recolonization. In such a case, we would expect the same amount of genetic heterogeneity between samples taken at the same place in different seasons or years. Two such studies have been conducted in the vicinity of Melbourne (Australia, latitude $37 \cdot 5^{\circ}$ ) by McKenzie and McKechnie (1981) and by Nielsen et al. (1985), providing similar results. Average $A d h-F$ frequencies were 70 and 74 per cent respectively, and almost all field samples were between 60 and 82 per cent. From these data, approximate values of $\mathrm{F}_{\mathrm{ST}}$, may be inferred to be about 0.02 , i.e., much lower than for the samples collected around Cordoba. Although more extensive investigations would be needed, these observations suggest that the microspatial-temporal stability of natural populations could be greater in Australia than in southern Spain and in other Mediterranean countries such as Greece and Egypt. An alternative hypothesis to explain the apparent instability of the Mediterranean populations would be the occurrence, for these populations, of divergent selective pressures leading to different equilibrium frequencies in different habitats. More precisely, a high frequency of $F$ allele would be favoured in wine cellars, while a much lower equilibrium would be favoured in field populations. A higher frequency of $A d h-F$ in wine cellar populations has been observed by various authors in Spain (Briscoe et al., 1975; Alonso-Moraga et al., 1985, 1986) and Canada (Hickey and McLean, 1980) but not in Australia (McKenzie and Parsons, 1974; McKenzie and McKecknie, 1978) nor in California (Marks et al., 1980) nor in France (Charles-Palabost et al., 1985; Capy et al., 1987, 1988). There is no general solution to this ecological problem. The strong association of $A d h-S$ with inversion 2L(t) (Aguade and Serra, 1980; Anderdon et al., 1987) could be important in selective processes. Further investigations are underway on the possible occurrence of two adaptive peaks at the $A d h$ locus in populations around the Mediterranean Sea.

Acknowledgements The help of D. Defaye, E. Pla and J. Sandrin is gratefully acknowledged. This work was supported by grants from IREB and PIREN. 


\section{REFERENCES}

AGUAADE, M. AND SERRA, L: 1980. Spanish cellar populations of Drosophila melanogaster. I. Study of variability at three different levels: quantitative, chromosomal and molecular. Genetika (Beograd), 12, 111-120.

ALONSO-MORAGA, A., MUNOZ-SERRANO, $\wedge$. AND RODERO, A. 1985. Variation of alloenzyme frequencies in Spanish field and cellar populations of Drosophila melanogasier. Génét. Sél. Evol., 17, 435-442.

ALONSO-MORAGA, A. AND MUNOZ-SERRANO, A. 1986. Allozyme polymorphism and linkage disequilibrium of $A d h$ and $-G p d h$ loci in wine cellar and field populations of Drosophila melanogaster. Experientia, 42, 1048-1050.

ANDERSON, P. R. AND OAKFSHOTT, J. G. 1984. Parallel geographical pattern of allozyme variation in two sibling Drosophila species. Nature, 308, 729-731.

ANDERSON, P. R., KNIBB. W. R. AND OAKESHOT', J. G. 1987. Observation on the extent of latitudinal clines for alcohol dehydrogenase and four chromosome inversions in Drosophila melanogaster. Genetica, 75, 81-88.

BRISCOE, D. E., ROBERTSON, A. AND MALPICA, J. M. 1975. Dominance at Adh locus in response of adult Drosophila melanogaster to environmental alcohol. Nature, $255,148-$ 149.

CAPY, P., DAVID, J. R., ALLEMAND, R., CARTON, Y., FEBVAY, G. AND KFRMAREC, A. 1986. Genetic analysis of Drosophila melanogaster in the French West Indies and comparison with populations from other parts of the world. Genetics, 69, 167-176.

CAPY, P., DAVID, J. R., CARTON, Y., PLA, E. AND STOCKEL, J. 1987. Grape breeding Drosophila communities in Southern France: short range variation in ecological and genetical structure of natural populations. Acta Oecol., Oecol. gener., $8,435-440$.

CAPY, P., DAVID, J. R., AND DELAY, B. 1988. Can we modify the genetic structure of a Drosophila natural population by releasing genetically marked flies? Genet. Iberica (in press).

CHARLES-PALABOST, L., LEHMANN, M. AND MERCOT, H. 1985. Allozyme variation in fourteen natural populations of Drosophila melanogaster collected from different regions of France. Génét. Sélec. Evol., 17, 201-210.

D^VID, J. R. 1982. Latitudinal variability of Drosophila melanogaster: allozyme frequencies divergence between European and Afrotropical populations. Biochem. Genet., $20,747-761$.

DAVID, J. R. 1983. An attempt to modify allelic frequencies at the Adh locus of a Drosophila melanogaster population in a tropical environment. Génét. Sél. Evol., 15, 495-500.

DAVID, J. R. AND CAPY, P. 1988. Genetic variation of I rosophila melanogaster natural populations. Trends in Genetics, 4, 106-111.

DAVID, J. R., MERCOT, H., CAPY, P., MCEVEY, S. F. AND VAN HERREWEGE, i. 1986. Alcohol tolerance and Adh gene frequencies in European and African populations of Drosophila melanogaster. Génét. Sel. Evol., 18, 405-416.

DAVID, J. R., CAPY, P., MCEVEY, S. F., DALY, K. AND BORAI, F. 1987. Latitudinal clines of $A d h$ gene frequencies in Drosophila melanogaster: a mediterranean instability. Droso. Inf. Serv. 66, 40-41.
ENDler, J. A. 1986. Natural Selection in the Wild. Princeton University Press, Princeton, New Jersey, 336pp.

GIRARD, P. AND PALABOST, L. 1976. Etude du polymorphisme enzymatique de 15 populations naturelles de Drosophila melanogaster. Arc. Zool. exp. gén., 117, 41-55.

GROSSMAN, A. 1. 1973. Study of alcohol dehydrogenase and $\alpha$-glycerophosphate dehydrogenase in the Israel natural populations of Drosophila melanogaster. Droso. Inf. Serv., $50,119-120$.

GROSSMAN, A. I., KORENOVA, L. (i. AND ULITSCAYA, L. E. 1970. The variability of $A d h$ locus in a natural population of Drosophila melanogaster. (in Russian). Genetika (Moscow), 6, 95-101.

HICKEY, D. A. AND MCL.F.AN, M. D. 1980. Selection for ethanol tolerance and ADH allozymes in natural populations of Drosophila melanogaster. Genet. Res., 36, 11-15.

JOHNSON, F. M. AND SCHAFFER, H. E. 1973. Isozyme variability in species of the genus Drosophila VII. Genotype-environment relationships in populations of Drosophila melanogaster from the Eastern United States. Biochem. Genet., 10, 149-163.

MARKS, R. W., BRITTNACKER, J. G., MCDONALD, J. F., PROUT, T. AND AYAlA, F. J. 1980. Wineries, Drosophila, alcohol and ADH. Oecologia, 47, 141-144.

MCKENZIE, J. A. AND MCKECHNIE, S. W. 1978. Ethanol tolerance and the Adh polymorphism in a natural population of Drosophila melanogaster. Nature, 272, 75-76.

MCKENZIE, J. A. AND McKECHNIE, S. W. 1981. The alcohol dehydrogenase polymorphism in a vineyard cellar population of Drosophila melanogaster. In Gibson, J. B. and Oakeshott, J. G. (eds) "Genetic Studies of Drosophila Populations", Australian Nat. Univ. Press, Canberra, pp. 201-215.

MCKENZIE, J. A. AND PARSONS, P. A. 1974. Microdifferentiation in a natural population of Drosophila melanogaster to alcohol in the environment. Genetics, 77, 385-394.

MUNOZ-SFRRANO, A., ALONSO-MORAGA, A. AND RODERO, A. 1985. Annual variation of enzyme polymorphism in four natural populations of Drosophila melanogaster occupying different niches. Genetica, 67, 121-129.

NILLSEN, K. M., HOFFMANN, A. A. AND MCKECHNIE, S. W. 1985. Population genetics of the metabolically related $A d h$, Gpdh and Tpi polymorphisms in Drosophila melanogaster: II. Temporal and spatial variation in an orchard population. Génét. Sél. Evol., 17, 41-58.

OAKESHOTT, J. G., GIBSON, J. B., ANDERSON, P. R., KNIBB, W. R., ANUERSON, D. G. AND CHAMBERS, G. K. 1982. Alcohol dehydrogenase and glycerol-3-phosphate dehydrogenase clines in Drosophila melanogaster on different continents. Evolution, 36, 86-96.

SINGH, R. S., HICKEY, D. A. AND DAVID, J. R. 1982. Genetic differentiation between geographically distant populations of Drosophila melanogaster. Genetics, 101, 235-256.

SMITH, M. R., CHAMBERS, G. K., BROOKS, L. D., COHAN, F. M AND COHAN, S. C. 1984. How many Adh clines on the West coast of North America? Droso. Inf. Serv., 60, 188 189.

VAN DFLDEN, W. 1982. The alcohol dehydrogenase polymorphism in Drosophila melanogaster. Selection at an enzyme locus. Evol. Biol., 15, 187-222.

WRIGHT, s. 1951. The genetical structure of populations. Ann. Eugen., 15, 323-354. 